NOTE

\title{
Streptococcus iniae type II infections in rainbow trout Oncorhynchus mykiss
}

\author{
D. Lahav ${ }^{1}$, M. Eyngor ${ }^{2}$, A. Hurvitz ${ }^{3}$, C. Ghittino ${ }^{4}$, A. Lublin ${ }^{2}$, A. Eldar ${ }^{2, *}$ \\ ${ }^{1}$ Department of Pathology, and ${ }^{2}$ Department of Poultry and Fish Diseases, Kimron Veterinary Institute, \\ POB 12, 50250 Bet-Dagan, Israel \\ ${ }^{3}$ Dan Fish Farm, Kibbutz Dan, 12245 Upper Galilee, Israel \\ ${ }^{4}$ Department of Fish Pathology, IZS-State Veterinary Institute, 06126 Perugia, Italy
}

\begin{abstract}
Clinical and pathological findings (anorexia, hemorrhage, lethargy, loss of orientation and exophthalmia) indicated that Streptococcus iniae type II is responsible for a fatal disease in rainbow trout. Histopathological findings revealed that $S$. iniae type II produces a systemic disease, including a diffuse necrotizing myositis. The distribution of viable bacteria in infected tissues substantiated the pathological findings, confirming that $S$. iniae type II is responsible for a generalized septic disease of rainbow trout.
\end{abstract}

KEY WORDS: Rainbow trout $\cdot$ Streptococcus iniae $\cdot$ Serotype $\cdot$ Pathology

Resale or republication not permitted without written consent of the publisher

\section{INTRODUCTION}

Streptococcus iniae was first described as a pathogen of fish in 1994, when it was cultured from diseased tilapines Oreochromis spp. and rainbow trout Onchorynchus mykiss in Israel (Eldar et al. 1994, 1995). A year later the same agent was isolated in the USA from infected tilapines and striped bass Morone saxitilis (Perera et al. 1994), suggesting the pathogen and its associated disease were widely distributed. Although the North American and Israeli isolates cluster in 2 distinct epidemiological clones (Eldar et al. 1997b), the pathological outcomes are similar (Eldar et al. 1995, Perera et al. 1994, Eldar \& Ghittino 1999), with losses that often exceed $50 \%$ of the population. Increased awareness and improved identification schemes have subsequently demonstrated that $S$. iniae is present in different parts of the world and among various fresh- and saltwater fish species (Zlotkin et al. 1998, Ferguson et al. 2000, Bromage \& Owens 2002, Colorni et al. 2002). Genetic profiles that characterize virulent and environmental strains have also been revealed (Weinstein et al. 1997, Fuller et al. 2001).
S. iniae has also been isolated from clinical specimens of human blood, urine and skin (Weinstein et al. 1997, Lau et al. 2003), in which it was associated with infections that can have a fatal course. S. iniae is, therefore, an emerging pathogen of increased clinical significance.

In Streptococccus iniae-infected rainbow trout, the disease is characterized by a subacute to acute course, with specific lesions of which the 'hallmarks' are panophthalmitis and meningitis; pathological changes in other organs are minor (Eldar \& Ghittino 1999). Recently, in Israel, novel virulent strains of $S$. iniae were isolated from diseased rainbow trout that showed major pathological changes, suggesting a severe generalized disease. The new strains were characterized as Serotype II strains; they differed from 'classical' type I strains by serological, phenotypic and genetic criteria (Bachrach et al. 2001). Serotype II strains are able to enter phagocytes and multiply within them, causing them subsequently to undergo death through apoptotic processes (Zlotkin et al. 2003). S. iniae type II strains have also been detected in the USA, indicating the wide distribution of $S$. iniae variants (Barnes et al. 
2003). In the present work we assessed the pathological outcomes of infections of rainbow trout by $S$. iniae serotype II. Our results indicate that Serotype II strains produce an acute septic disease accompanied by multisystem organ involvement.

\section{MATERIALS AND METHODS}

Sampling procedure for pathology and bacteriological analysis. Specimens were collected from 2 trout farms located in northern Israel (Upper Galilee) which are supplied with water at a constant temperature of $16^{\circ} \mathrm{C}$. At the time of collection both farms were experiencing heavy mortalities, and bacteriological examination (30 fish from each farm, 50 to $350 \mathrm{~g}$ each) revealed pure colonies of $\beta$-hemolytic Gram-positive cocci. Bacteriological identification (Eldar et al. 1995), authenticated by PCR analysis (Zlotkin et al. 1998), confirmed the presence of arginine dehydrolase-negative isolates of Streptococcus iniae. PCR analysis with the p14 primer did not produce the $750 \mathrm{bp}$ band, indicating that all current isolates were of type II (Bachrach et al. 2001). Tissues (brain, heart, spleen, kidney, liver, intestine, gills and muscle) from 10 diseased rainbow trout were fixed in $10 \%$ neutral buffered formalin and stained with hematoxylin and eosin (HE). Gross lesions were recorded.

Distribution of bacteria in tissues. Bacterial colonyforming units (CFUs) were counted in the tissues of 20 rainbow trout (100 to $200 \mathrm{~g}$ each), infected with Streptococcus iniae type II and showing clinical signs of streptococcosis (darkening of the skin combined with multifocal ecchymoses, lethargy, loss of orientation and ocular pathologies). Organs (brain, heart, spleen, kidney, liver, intestine, gills and muscle) were weighed and blended over a 60-mesh grid. Tissue homogenate samples $(1 \mathrm{~g}$ ) were suspended in $10 \mathrm{ml}$ phosphatebuffered saline (PBS) (15 mM Na $2 \mathrm{HPO}_{4}, 145 \mathrm{mM} \mathrm{NaCl}$, $\mathrm{pH}$ 7.20) supplemented with $0.2 \%$ Triton X-100 (Sigma) and serially diluted. The bacterial CFU population was determined by plate counting.

The bacterial loads in tissues of rainbow trout infected by Streptococcus iniae type I were assessed with a 2-step cohabitation method. First, 10 naive rainbow trout (50 to $80 \mathrm{~g}$ each) were infected by intraperitoneal inoculation of $\left(7.5 \times 10^{5} \mathrm{CFU} \mathrm{fish}^{-1}\right)$ virulent $S$. iniae Dan-15 (type I strain), as described previously (Eldar et al. 1997a). Then, on Day 10 post-infection, 5 clinically diseased fish were removed and added to a group of 50 naïve rainbow trout (100 to $150 \mathrm{~g}$ each). The latter fish were infected by cohabitation, a process that closely resembled natural disease acquisition. Progress of the disease was monitored daily, and fish were considered to be infected by $S$. iniae when they simultaneously exhibited 3 of the following 4 clinical signs: lethargy, black discoloration, loss of orientation and ocular pathologies. On Day 14 of cohabitation, 30 of the 50 fish exhibited clinical signs of the disease, and at this point 20 diseased fish were randomly chosen and sacrificed for bacteriological analysis. Bacterial counts were carried out as previously described. The re-isolation of $S$. iniae Dan-15 was confirmed by means of phenotypic and genetic tools (Bachrach et al. 2001).

Statistical analysis. The results are presented as the means \pm SDs of means of the data (CFU g ${ }^{-1}$ tissue) obtained for each organ in triplicate. The data were transformed to decimal logarithmic values. To overcome the uncertainty whether these values were distributed normally, a non-parametric procedure was applied, i.e. analysis of variance for the logarithmic transformations of Streptococcus iniae CFU counts. Duncan's multiple range test was applied to the differences between the CFU counts obtained in different organs. The statistical analysis was performed with SAS software (Alice 1985).

\section{RESULTS AND DISCUSSION}

The major gross pathological signs that characterized Streptococcus iniae type II infection included lethargy, discoloration, gill pallor, bilateral corneal opacity and exophthalmia (present in 80 to $100 \%$ of the fish). Hemorrhage in the anterior chamber of the eye was observed in $30 \%$ of the diseased fish; inflammation of the anus in $10 \%$; and external and internal hemorrhage in $40 \%$. Skin (ecchymotic) hemorrhage was present mainly on the lateral sides and around the anal area; hemorrhage was more pronounced in the internal organs (particularly the spleen and the fat tissue around the intestine), and consisted of multifocal to coalescent pettechiae. The most consistent visceral abnormality was splenomegaly, observed in $70 \%$ of the fish. Other internal lesions (hepatic lesions, congested kidneys, dilated intestine) were present, if at all, on less then $10 \%$ of the fish. These macroscopic findings point to an acute disease that differs from that observed in $S$. iniae type I infection. Histopathological findings, particularly those of the somatic muscles, confirmed this interpretation. While no injuries were observed in the skeletal muscles of fish infected by $S$. iniae type I, those of fish infected by $S$. iniae type II showed multifocal to diffuse areas of degeneration and necrosis, accompanied by heterophilic histiocytic infiltration. Necrotic fibers that had lost their striations appeared in small clumps; the cytoplasm of the individual cells was vacuolated and hypereosinophilic (Fig. 1). S. iniae type II bacterial counts in skeletal muscles $\left(4.5 \times 10^{7} \mathrm{CFU} \mathrm{g}^{-1}\right)$ were unexpectedly high, being second only to those in 
the central nervous system (CNS) $(3 \times$ $\left.10^{8} \mathrm{CFU} \mathrm{g}^{-1} ; \mathrm{p}<0.05\right)$.

As described previously for Streptococcus iniae type I infections (Eldar \& Ghittino 1999), the present clinical findings of lethargy and loss of orientation correlated with intracranial edema (100\% of the fish) resulting from CNS meningeal infection and damage. In addition, peripheral autonomic ganglia, especially those next to the olfactory tract, showed multifocal areas of subacute ganglionitis with histiocytic infiltration and foci of neuronal necrosis (hypereosinophilia, vacuolation of the cytoplasm and karyolysis). Although CNS lesions resemble those of type I strains, $S$. iniae type II infections were characterized by a significant augmentation in the count of viable bacteria in brain tissue $\left(7 \times 10^{5} \mathrm{CFU} \mathrm{g}^{-1}\right.$ in cases of infection by $S$. iniae type I versus $3 \times 10^{8} \mathrm{CFU} \mathrm{g}^{-1}$ in infections by $S$. iniae type II, p $<0.005$; Table 1 ). Nonetheless, in both cases the highest bacterial load was found in the CNS, confirming $S$. iniae neurotropism.

Bacterial counts in infected tissues other then the CNS (Table 1) confirmed that Streptococcus iniae type II is responsible for an overwhelming septic disease characterized by large numbers of live bacteria, in accordance with similar models described in warmblooded animals (Saetre et al. 2000, Yuste et al. 2002). The histopathological findings of the viscera were consistent with acute bacterial infection: there was mild to moderate centrilobular hepatitis with histiocytic infiltration in the liver; hyaline droplets were observed in the cytoplasm of tubular cells in the kidneys, and there

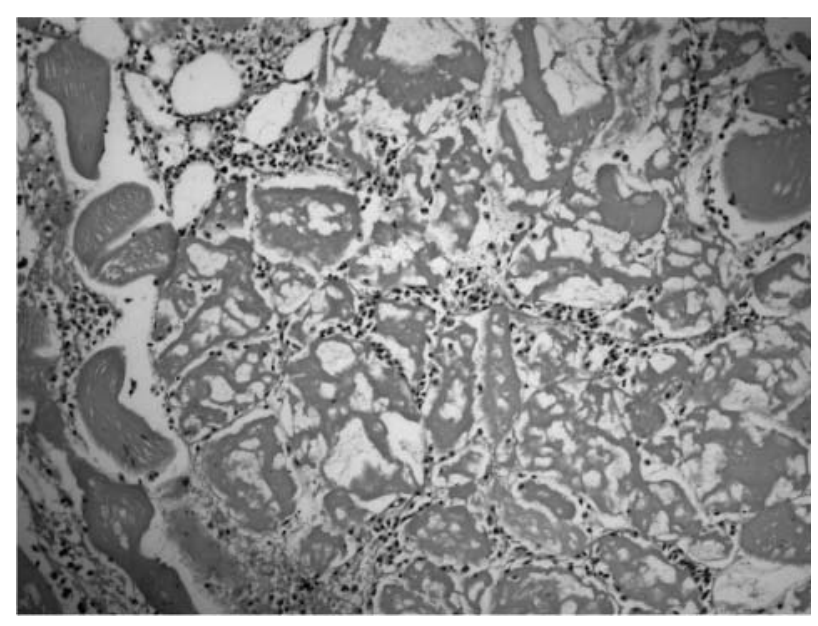

Fig. 1. Oncorhynchus mykiss infected by Streptococcus iniae type II. Striated muscle, temporal region: severe acute diffuse myositis and necrosis. HE $\times 400$ was mild lymphocyte depletion of interstitial tissue; and there was severe congestion in the spleen.

The augmented capability of Streptococcus iniae type II strains to survive in fish phagocytes and to induce their apoptotic death was recently suggested to be part of an advantageous mechanism that plays a critical role in the establishment of a generalized septic disease (Zlotkin et al. 2003). The data generated in the present study correlate with and extend previous results, and indicate that the augmented invasiveness of $S$. iniae type II also extends to parenchymal tissues, and so leads to a generalized septic disease. Although $S$. iniae type II infection results in a septic condition with multisystemic organ involvement, the main clinical sign, CNS malfunction, resembles a similar condition in warm-blooded animals and humans, in which up to $70 \%$ of patients with sepsis develop CNS symptoms known as septic encephalopathy (Harris 1987, Pfister et al. 1993, Bone 1994, Cottagnoud et al. 2002). The question of whether a pathogen ( $S$. iniae type II) that proliferates in internal tissues more successfully than another ( $S$. iniae type I) is of higher virulence, or vice versa, is complex and beyond the scope of this report.

Acknowledgements. This work was supported by EU funding (QLK2-CT-2000-01049.

\section{LITERATURE CITED}

Alice A (1985) SAS user's guide: statistics, Vol 5. SAS Institute, Cary, NC

Bachrach G, Zlotkin A, Hurvitz A, Evans DL, Eldar A (2001) Recovery of Streptococcus iniae from diseased fish previously vaccinated with a Streptococcus vaccine. Appl Environ Microbiol 67:3756-3758

Barnes AC, Young FM, Horne MT, Ellis EA (2003) Streptococcus iniae: serological differences, presence of capsule and resistance to immune serum killing. Dis Aquat Org 53: 241-247

Bone RC (1994) Gram-positive organisms and sepsis. Arch Intern Med 154:26-34 
Bromage ES, Owens L (2002) Infection of barramundi Lates calcarifer with Streptococcus iniae: effects of different routes of exposure. Dis Aquat Org 52:199-205

Colorni A, Diamant A, Eldar A, Kvitt H, Zlotkin A (2002) Streptococcus iniae infections in Red Sea cage-cultured and wild fishes. Dis Aquat Org 49:165-170

Cottagnoud P, Acosta F, Cottagnoud M, Tauber MG (2002) Cefipime is efficacious against penicillin- and quinoloneresistant pneumococci in experimental meningitis. J Antimicrob Chemother 49:327-330

Eldar A, Ghittino C (1999) Lactococcus garvieae and Streptococcus iniae infections in rainbow trout Oncorhynchus mykiss: similar, but different diseases. Dis Aquat Org 36: $227-231$

Eldar A, Bejerano Y, Bercovier H (1994) Streptococcus shiloi and Streptococcus difficile: two new streptococcal species causing a meningoencephalitis in fish. Curr Microbiol 28:139-143

Eldar A, Frelier PF, Assenta L, Varner PW, Lawhon S, Bercovier H (1995) Streptococcus shiloi, the name for an agent causing septicemic infection in fish, is as junior synonym of Streptococcus iniae. Int J Syst Bacteriol 45:840-842

Eldar A, Hurwitz A, Bercovier H (1997a) Development and efficacy of a streptococcal vaccine for the Israeli trout farming. Vet Immunol Immunopathol 56:175-183

Eldar A, Lawhon S, Frelier PF, Asanta L, Simpson BR, Varner PW, Bercovier H (1997b) DNA restriction length polymorphisms of 16S rRNA and of whole rRNA genes (ribotyping) of $S$. iniae isolates from the United States and Israel. FEMS Microbiol Lett 151:155-162

Ferguson HW, St John VS, Roach CJ, Willoughby S, Parker C, Ryan R (2000) Caribbean reef fish mortality associated

Editorial responsibility: David Bruno, Aberdeen, UK with Streptococcus iniae. Vet Rec 147:662-664

Fuller JD, Bast DJ, Nizet V, Low DE, de Azavedo JCS (2001) Streptococcus iniae virulence is associated with a distinct genetic profile. Infect Immun 69:1994-2000

Harris RL (1987) Manifestations of sepsis. Arch Intern Med 147:1895-1907

Lau SK, Woo PC, Tse H, Leung KW, Wong SS, Yuen KY (2003) Invasive Streptococcus iniae infections outside North America. J Clin Microbiol 41:1004-1009

Perera, RP, Johnson SK, Collins MD, Lewis DH (1994) Streptococcus iniae associated with mortality of Tilapia nilotica x T. aurea hybrids. J Aquat Anim Health 6:335-340

Pfister HW, Feiden W, Einhaupl KM (1993) Spectrum of complications during bacterial meningitis in adults: Results of a prospective clinical study. Arch Neurol 50:575-581

Saetre T, Hoiby EA, Aspelin T, Lermark G, Lyberg T (2000) Acute serogroup A streptococcal shock: A porcine model. J Infect Dis 182:133-141

Weinstein MR., Litt M, Kertesz DA, Wyper P and 8 others (1997) Invasive infections due to a fish pathogen, Streptococcus iniae. N Engl J Med 337:589-594

Yuste J, Lado I, Fenoll A, Ahuilar L, Gimenez MJ, Casal J (2002) $\beta$-Lactam modification of the bacteraemic profile and its relationship with mortality in a pneumococcal mouse sepsis model. J Antimicrob Chemother 49:331-335

Zlotkin A, Hershko H, Eldar A (1998) Possible transmission of Streptococcus iniae from wild to cultured marine fish. Appl Env Microbiol 64:4065-4067

Zlotkin A, Chilmonczyk S, Eyngor M, Hurvitz A, Ghittino C, Eldar A (2003) Trojan horse effect: phagocyte-mediated Streptococcus iniae infection of fish. Infect Immun 71: 2318-2325

Submitted: June 19, 2003; Accepted: June 22, 2004

Proofs received from author(s): October 20, 2004 